\title{
Molecular biological characterization of enterovirus variant isolated from patients with aseptic meningitis
}

\author{
Yong-Tae Jung, ${ }^{1}$ Gum-Ryong $\mathrm{Kim}^{1}$ and \\ Soon-Young Paik ${ }^{2}$ \\ 1 Department of Microbiology, College of Medicine, \\ The Catholic University of Korea,Seoul, 137-701, Korea. \\ 2 Corresponding Author \\ Accepted 2 June 1998
}

Abbreviations: 5'-NCR, 5'-noncoding region; RGD, arginine-glycine- aspartic acid; RT$P C R$, reverse transcription-polymerase chain reaction; RFLP, restriction fragment length polymorphism; OPT, oligopyrimidine tract; CSF, cerebrospinal fluid

\begin{abstract}
In Korea, there was a big outbreak of aseptic meningitis in 1993. Six clinical isolates of enterovirus were obtained from patients with aseptic meningitis and were identified as echovirus type 9 by serotyping with a pool of neutralizing antisera. For molecular characterization of the isolates, the nucleotide sequences of 5'-noncoding region (NCR), VP4, VP2, VP1, $2 A$ and $2 C$ regions of the isolates were compared with the corresponding regions of echovirus type 9 Hill and Barty strains. Unlike Hill strain, Barty strain contained a $\mathrm{C}$-terminal extension to the capsid protein VP1 with an RGD (argnine-glycine-aspartic acid) motif. To determine whether similar structural features were present in our isolates, their nucleotide sequences including the VP1 region were analyzed. All isolates exhibited the VP1 extension with the RGD motif. We concluded the Korean isolates in the year of 1993 as the echovirus type 9 Barty strain although the isolates showed $\mathbf{1 5 - 2 0 \%}$ nucleotide sequence differences in the several genomic regions.
\end{abstract}

Keywords: Aseptic Meningitis, enterovirus, RT-PCR, RFLP assay

\section{Introduction}

Enterovirus belongs to the picornavirus family which includes poliovirus, coxsackievirus $A$ and $B$, echovirus and human enterovirus (Melnick, 1990). Many enteroviruses cause diseases ranging from a common cold to more severe pathogenesis such as paralysis, myocarditis, encephalitis and aseptic meningitis (Grist et al., 1978). The aseptic meningitis is generally considered mild in that neurological sequale and mental impairments are accompanied rarely in children under the age of one. In a temperate zone, aseptic meningitis caused by enteroviral infection is prevalent in summer and autumn, and are observed approximately five times more severe patho-genesis in children under the age of ten (Feigin and Cherry, 1987; Rotbart et al., 1991). Nonpolio enterovirus accounts for $90 \%$ of all cases of aseptic meningitis (Berlin et al., 1993).

From April to August of 1993, there was a big outbreak of aseptic meningitis in Korea (Kim et al., 1997). More than 4,000 patients under the age of ten were hospitalized during the spread of this country-wide epidemic. Echovirus type 3 was isolated from the patients of aseptic meningitis in 1994, and echovirus type 7 and coxsackie virus type B3 were identified as the culprit for aseptic meningitis in 1995 (Kim et al., 1996). Although enterovirus infection can be diagnosed by isolating virus from cerebrospinal fluids (CSF), blood, and other affected organs, the cul-turing of enterovirus are frequently unsuccessful due to poor growth (Lipson et al., 1988). Recently, PCR has been used to detect the enterovirus RNA for a direct and rapid clinical diagnosis of enteroviral infections (Hyypia et al., 1989; Rotbart et al., 1990; Zoll et al., 1992). In the earlier study, we identified the isolates obtained from CSF of patients with aseptic meningitis in 1993 to be echovirus type 9 based on serotyping with a panel of neutralizing antisera (Kim et al., 1997). We also showed that the isolates exhibited pathogenicity for newborn mice. The two echovirus type 9 strains, Hill and Barty, have been previously shown to be different each other in pathogenicity for new born mice as well as in a number of in vitro characteristics which depend on viral capsid structure (Rosenwirth et al., 1986). The complete nucleotide sequences of the both strains have been recently reported (Zimmermann et al., 1996).

Since serotyping with a panel of neutralizing antisera lacks the sensitivity to distinguish the different strains with the same serotype, we have presently examined the genetic diversity and molecular characteristics of the isolates by sequence analysis of different regions of the viral genome: the nucleotide sequences of cDNA clones representing the $5^{\prime}$-noncoding region (NCR), capsid regions, $2 \mathrm{~A}$ protease regions and $2 \mathrm{C}$ helicase regions of six isolates were determined and compared with both Hill and Barty strains of echovirus type 9.

\section{Materials and Methods}

\section{Viruses and cells}


Clinical isolates were obtained in 1993 in our laboratory (Kim et al., 1997). Vero E6 cell (ATCC C1008 CRL 1586), coxsackie virus B3 (Nancy strain, ATCC VR-30), coxsackie virus A9 (Griggs strain, ATCC VR-1311), and echovirus type 9 (Hill strain, ATCC VR-39) were purchased from American Type Culture Collection (Rockville, MD, USA). Maintenance medium consisted of Eagle's minimum essential medium with $10 \%$ fetal calf serum, $4 \%$ Lglutamine $(200 \mathrm{mM}, 100 \times$ : Gibco, Grand Island, NY, USA) and $1 \%$ non-essential amino acid (10 mM of each amino acids: MA. Bioproducts, Walkersville, MD, USA) (Kim and Mckee, 1985). Coxsackie virus B3, coxsackie virus $A 9$, echovirus type 9 and the six isolates named as AMC 2, 3, 9, 11, 14, 16 were propagated in the monolayers of Vero E6 cells, and were used as reference viruses.

\section{RNA extraction}

When nearly all of the cells displayed viral specific immunofluorescence by immunofluorescence antibody staining, the cells were harvested and then the RNAs from virus infected Vero E6 cells were extracted by using a Ultraspec-II RNA kit (Biotecx Laboratories, Inc., Huston, Texas, USA). RNA was prepared according to the procedures provided by the suppliers.

\section{Primers}

Primer sequences were selected from the conserved regions of the enterovirus genome, and their sequences and locations are shown in Table 1 (Samuelson et al., 1995; Olive et al., 1990; Kopecka et al., 1995). 5'-NCR was found to be highly conserved in the majority of the enterovirus serotypes which have been sequenced to date. To identify the isolates by restriction fragment length polymorphism (RFLP) assay, 5'-NCR of the six isolates were amplified. For the whole sequencing of $5^{\prime}-$ NCR and VP4-VP2 region, the 643 bp products were obtained by using primer combination of $5 \mathrm{NC}$ and EU2 (Pair A, Table 1), and the 652 bp by EU3 and EU4 (Pair C, Table 1).

\section{RT-PCR (reverse transcription-polymerase chain reaction)}

The cDNA from RNA was synthesized at $42^{\circ} \mathrm{C}$ for 30 min in a $20 \mu \mathrm{l}$ solution containing $50 \mathrm{mM}$ Tris- $\mathrm{HCl}(\mathrm{pH}$ 8.3), $50 \mathrm{mM} \mathrm{KCl}, 10 \mathrm{mM} \mathrm{MgCl} 23 \mathrm{mM}$ DTT, 20 units of RAV2 reverse transcriptase (Boehringer Mannheim $\mathrm{GmBH}$, Germany), $5 \mu \mathrm{g}$ of RNA and $4 \mu \mathrm{g}$ of random hexamers. Thirty cycles of $1 \mathrm{~min}$ denaturation at $95^{\circ} \mathrm{C}, 1$ min annealing at $55^{\circ} \mathrm{C}$ and $1 \mathrm{~min}$ extension at $72^{\circ} \mathrm{C}$ were carried out in a thermal cycler (Thermolyne Barnstead, Pubuque, IA, USA) (Zoll et al., 1992). The reaction mixture for PCR contained $25 \mathrm{mM}$ Tris- $\mathrm{HCl}$ (pH 9.0), 50 $\mathrm{mM} \mathrm{KCl}, 2 \mathrm{mM} \mathrm{MgCl} 2,1 \mathrm{mM}$ DTT and 1.3 units of Ampli-Taq DNA poly-merase (Perkin-Elmer, Norwalk, CT, USA)

\section{Restriction endonuclease digestion}

Table 1. List of primers for CDNA synthesis and RT-PCR

\begin{tabular}{|c|c|c|}
\hline \multicolumn{2}{|c|}{ Primers Position ${ }^{1}$} & \multirow[t]{2}{*}{ Sequences } \\
\hline Pair A & & \\
\hline $5 \mathrm{NC}$ & $1-17$ & $\begin{array}{l}\text { 5'- TCA GCG GCC GCT TAA AAC AGC CTG } \\
\text { TGG G -3' }\end{array}$ \\
\hline EU2 & $626-643$ & 5'- CAC CGG ATG GCC AAT CCA -3' \\
\hline $\begin{array}{l}\text { Pair B } \\
\text { UE1 } \\
\text { UE3 }\end{array}$ & $\begin{array}{l}160-180 \\
580-599\end{array}$ & $\begin{array}{l}\text { 5'- CAA GCA CTT CTG TTT CCC CGG -3' } \\
\text { 5'- ATT GTC ACC ATA AGC AGC CA -3' }\end{array}$ \\
\hline $\begin{array}{l}\text { Pair C } \\
\text { EU3 } \\
\text { EU4 }\end{array}$ & $\begin{array}{l}542-558 \\
1176-1195\end{array}$ & $\begin{array}{l}\text { 5'- CTA CTT TGG GTG TCC G -3' } \\
\text { 5'- GGT AAC TTC CAC CAC CAG CC -3' }\end{array}$ \\
\hline $\begin{array}{l}\text { Pair D } \\
\text { Evp1 } \\
\text { Evp3 }\end{array}$ & $\begin{array}{l}2187-2206 \\
2587-2606\end{array}$ & $\begin{array}{l}\text { 5'- GGI ACI CAT GTI ATI TGG GA -3' } \\
\text { 5'- TGT CTI GTT TGC ATI GTG TC -3' }\end{array}$ \\
\hline $\begin{array}{l}\text { Pair E } \\
2 \mathrm{~A} 1 \\
2 \mathrm{~A} 2\end{array}$ & $\begin{array}{l}3179-3198 \\
3635-3661\end{array}$ & $\begin{array}{l}\text { 5'- ACC AAA GCT TGG GTG CCG CG -3' } \\
\text { 5'- CCT TAG GAT CCC ACC ACA GTC CCC } \\
\text { TGG -3' }\end{array}$ \\
\hline $\begin{array}{l}\text { Pair F } \\
2 \mathrm{C} 1 \\
2 \mathrm{C} 2\end{array}$ & $\begin{array}{l}4396-4419 \\
5009-5033\end{array}$ & $\begin{array}{l}\text { 5'- CAT ACA GTT CAA GTC CAA ATG CCG -3' } \\
\text { 5'- TGT CTA GCG AGT ATC TGA CCT GTG -3' }\end{array}$ \\
\hline
\end{tabular}

${ }^{1}$ Positions refer to the echovirus type 9 (Hill strain) sequence. 
For restriction enzyme analysis, $10 \mu$ of the DNA solution obtained by PCR was digested by subgroup specific restriction enzymes in a final volume of $20 \mu$ l with restriction buffer. The reactions were carried out by the method recommended by the supplier (Boehringer Mannheim $\mathrm{GmBH}$, Germany) and the digests were analyzed on a $2 \%$ agarose gel (Ultra Pure, Bethesda Research Laboratories, Bethesda, MD, USA) in $0.5 \times$ TBE buffer containing $0.5 \mu \mathrm{g} / \mathrm{ml}$ of ethidium bromide (Jung and Kim, 1995).

\section{Cloning of PCR product}

To determine the nucleotide sequence of the $5^{1}-\mathrm{NCR}$, capsid protein, $2 \mathrm{~A}$ protease and $2 \mathrm{C}$ helicase, $\mathrm{PCR}$ amplicons generated by using each primers were cloned into pCRII vector (Invitrogen, Carlsbad, CA, USA).

\section{Nucleotide sequence analysis}

The plasmid DNA was sequenced by the dideoxy-chaintermination method using Sequenace version 2.0 DNA sequencing kit (United States Biochemical, Cleveland, OH, USA) (Sanger et al., 1977). Annealing mixture containing $7 \mu$ l of DNA (3-5 $\mu \mathrm{g}$ ), $2 \mu$ l of reaction buffer and 1 $\mu$ of primer was heated for $2 \min$ at $65^{\circ} \mathrm{C}$, prior to being cooled to $35^{\circ} \mathrm{C}$ for $15-30 \mathrm{~min}$. One $\mu \mathrm{l}$ of 0.1 M DTT, $2 \mu \mathrm{l}$ of labelling mix (diluted 1:5), $0.5 \mu \mathrm{l}$ of $\left[{ }^{35} \mathrm{~S}\right] \mathrm{dATP}$, and 2 $\mu$ of polymerase were added to the annealed mixture for labelling. The labelled mixture $(3.5 \mu \mathrm{l})$ was transferred to each termination tube and then incubated at $37^{\circ} \mathrm{C}$ for $5-10 \mathrm{~min}$. The Reaction was stopped by adding $4 \mu \mathrm{l}$ of stop solution. Samples were electrophoresed on $6 \%$ denaturing gel at $1600 \mathrm{~V}$.

\section{Results}

Virus identification and detection of viral genome

Cytopathic effect of Vero E6 cells was observed on the day 2 after the inoculation. More than $90 \%$ of the cells showed cytopathic effect on the day 5 . All of the isolates were identified as echovirus type 9 by using pools of neutralizing antisera; monovalent neutralizing antisera were used against echovirus type 9 (by Dr. W. L. Lim at the Virus Unit, Queen Mary Hospital, Clinical Pathology, Hong Kong). Bacteriological cultures from each CSF were sterile, and serological studies by immunofluorescence antibody staining for leptospira or rickettsia infection were negative. For the molecular identification of the isolates, we used the RT-PCR method. RNAs of three reference viruses and six isolates were extracted in two to three days after the inoculation. The PCR products of $440 \mathrm{bp}$ were amplified from nine viruses with the 5'-NCR primer pair B (Table 1, Figure 1A). RNA extracted from the uninfected normal Vero E6 and RNA virus such as Hantaan and Seoul viruses were not amplified with the same primer set $B$ (data not shown). These results indicated that six AMC isolates (AMC 2, 3, 9, 11, 14, 16) from CSF specimens were enteroviruses, however, the enterovirus species were not differentiated. To differentiate the species of enteroviruses, the RFLP pattern of the 5'-NCR amplified products were analyzed. When the 5'-NCR products of the six isolates were digested with Taql, the two generated fragments were $281 \mathrm{bp}$ and $91 \mathrm{bp}$ sizes as echovirus type 9 (Figure 2A). The RFLP patterns (340 bp and $100 \mathrm{bp}$ fragments) of the six isolates upon digestion with Ddel was also similar to that of echovirus type 9 (Figure 2B). The pattern generated with Styl, however, was not identical with that of echovirus type 9 (Figure 1B). To confirm and analyze the base substitutions of the isolates, we sequenced the $5^{\prime}-\mathrm{NCR}$ of AMC 2 and compared the sequence with that of other enteroviruses (Figure 3 and Figure 4, discussed below). The results indicated that they belonged to echovirus type 9, even though there were many $U$ to $C$ and $A$ to $G$ substitutions and other

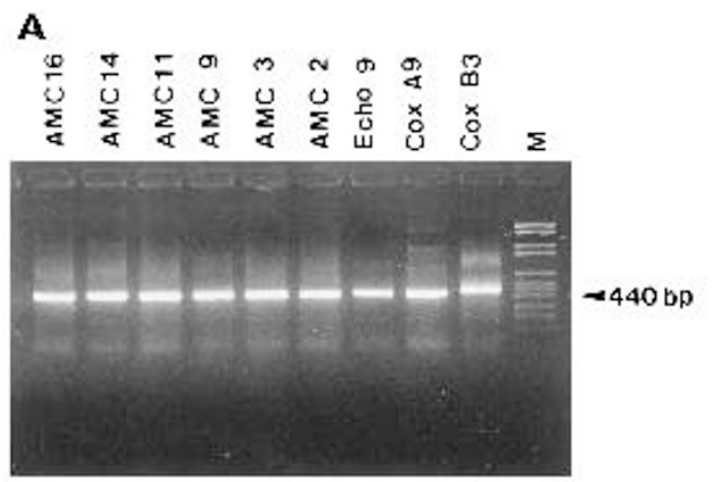

B

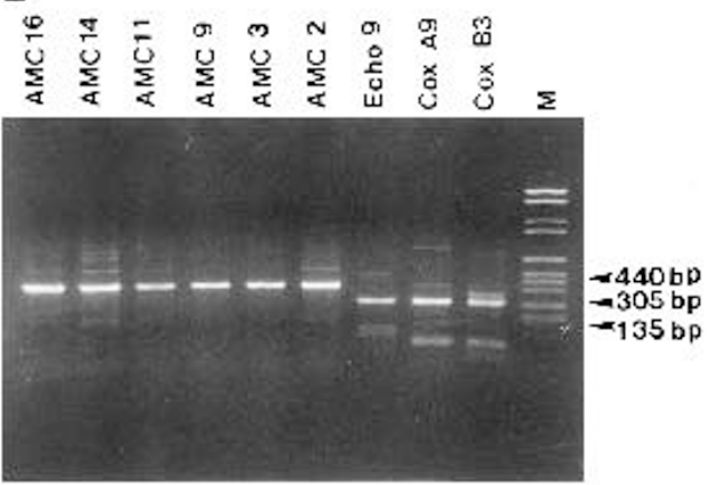

Figure 1. A. Agarose gel electrophoresis of PCR product resulting from amplification of 5 -NCR using primer pair B was carried out on $2 \%$ agarose gel. B. Restriction enzyme digestion pattern of PCR products from three different prototype strains and six clinical isolates with Styl. Cox B3, coxsackievirus B3; Cox A9, coxsackievirus A9; Echo 9, echovirus type 9;AMC2, 3, 9, 11, 14, 16, the isolates; M, DNA size marker VI (Boehringer Mannheim $\mathrm{GmBH}$, Germany). 
A

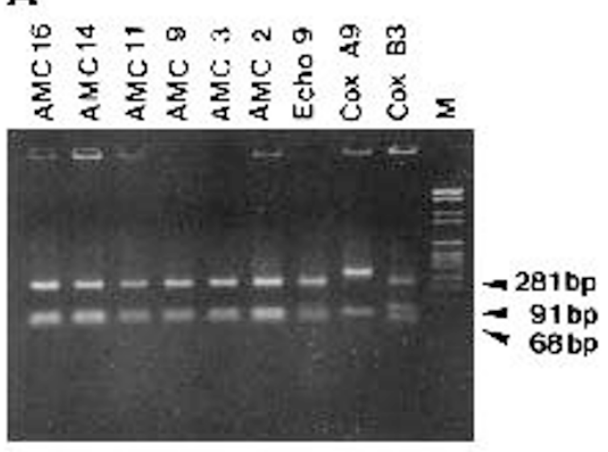

B

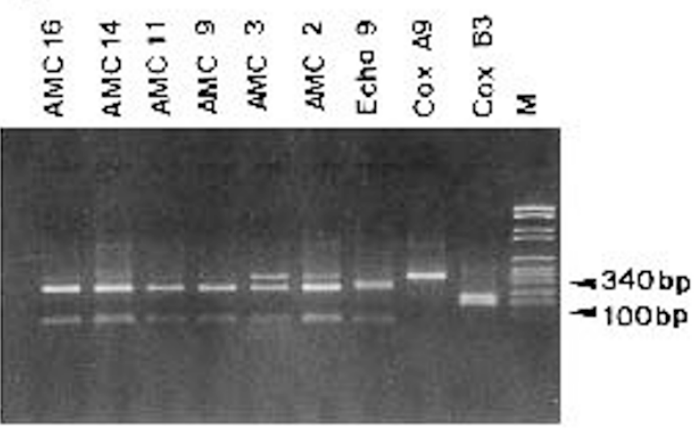

Figure 2. Restriction enzyme digestion pattern of PCR products from thereference strains and six clinical isolates with $\operatorname{Taql}(\mathrm{A})$ and Ddel (B). Cox B3, coxsackievirus B3 Cox A9, coxsackievirus A9; Echo 9, echovirus type 9; AMC 2, 3, 9, 11, 14, 16, the isolates; $\mathrm{M}$, DNA size marker VI (Boehringer Mannheim GmBH, Germany).

mutations in the isolates resulting losses of restriction sites.

\section{5'-NCR}

5 -NCR of enterovirus contains the internal ribosome entry site (IRES) element and oligopyrimidine tract (OPT) sequence of 5'-TTTCCTTTTA-3' which is crucial for efficient initiation of translation (Nicholson et al., 1991; Meerovitch et al., 1991). Sequences of the downstream 5'-NCR of seven echoviruses with different neurovirulence phenotype were reported (Romero et al., 1995). The neurovirulent serotype echovirus 2 and echovirus 12 showed little variations at this position. The 5'-NCR of six isolates were amplified, sequenced, and found that they possessed the upstream OPT sequence of 5'-TTTC CTTTTA-3', the sequences being identical to those of the five echoviruses having the neurovirulent phenotype (Figure 3).

\section{Analysis of 5'-NCR and VP4-VP2 sequence}

The 1,366 bp of AMC 2 isolate were sequenced from the 5'-NCR to VP4-VP2 region (GenBank accession

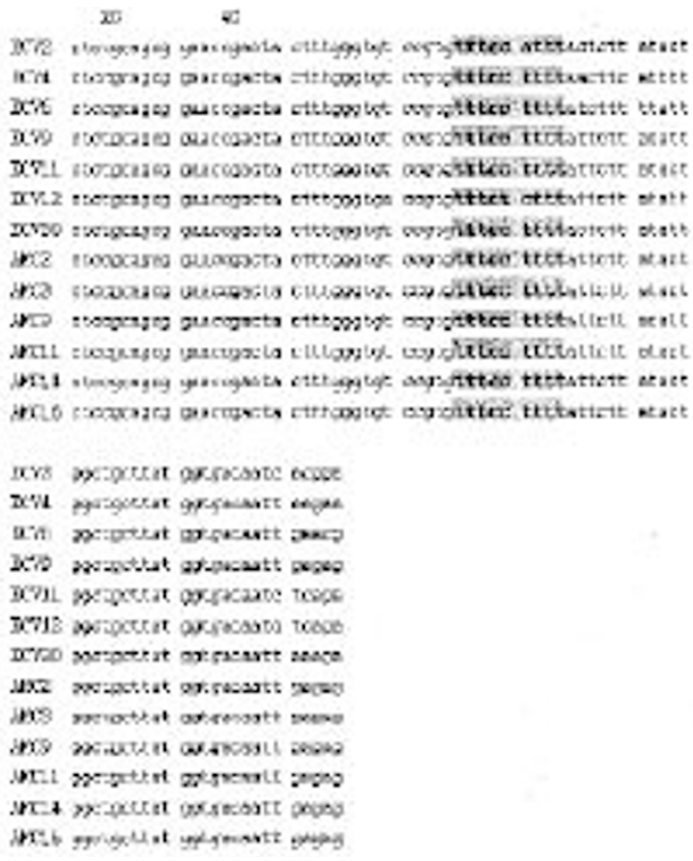

Figure 3. Sequence alignment of the echovirus down stream of $5^{\prime}$-NCR.Upstream half of the oligopyrimidine tract (OPT) is shown in bold and shade. $5^{\prime}$-TTTCC-3' domain may base pair with complementary sequence within the host $18 \mathrm{~S}$ rRNA.

\#U77070). It showed $85 \%$ nucleotide sequence homology to that of echovirus 9 (Barty strain). The homology in the $5 '$-NCR was higher with about $87 \%$ with echovirus 9 (Barty strain). The sequence was less homologous with other enterovirus types. AMC 2 isolate had $82 \%$ nucleotide sequence homology and $92 \%$ amino acid sequence homology with VP4 region of the Barty strain. Prototype (Hill strain) and AMC 2 isolate shared $76 \%$ nucleotide sequence homology and $87 \%$ amino acid sequence homologies in VP4 region. The VP2 region of AMC 2 isolate shared an $82 \%$ nucleotide sequence homology with Hill and Barty strain, and $98 \%$ and $96 \%$ amino acid sequence homologies with Hill and Barty strain, respectively (Table 2).

\section{Partial sequence comparison of VP1/2A region}

It has been shown previously that, unlike other enteroviruses, the coxsackievirus A9 prototype strain (Griggs) and echovirus type 9 (Barty strain) contain a C-terminal extension to the capsid protein VP1 and that there is an RGD (arginine-glycine-aspartic acid) motif within the extension (Zimmermann et al., 1996). To determine whether the VP1 C-terminal extension found in the Barty strain is also present in our isolates, PCR product (419 bp) derived from the region of VP1/2A junction was obtained from cDNA of the six isolates using primer Evp1 and Evp2 (Jung 
Table 2. Comparison of nucleotide homology of AMC 2 isolate with otherenterovirus members (\%)

\begin{tabular}{lcccccc}
\hline & 5'-NCR & VP4 & VP2 & VP3/VP1 & VP1/2A & 2C \\
\hline Echo 6 & 84.6 & 74.4 & 73.2 & 66.8 & 73.7 & 80.3 \\
Echo 9 (Hill) & 83.3 & 76.3 & 82.6 & 79.8 & 76.7 & 80.3 \\
Echo 9 (Barty) & 87.6 & 82.0 & 82.6 & 83.4 & 77.7 & 83.3 \\
Echo 11 & 82.5 & 75.8 & 76.8 & 65.3 & 66.5 & 80.7 \\
Echo 12 & 81.4 & 80.2 & 77.9 & 65.0 & 73.1 & 82.6 \\
Coxsackie B1 & 82.9 & 75.8 & 77.9 & 60.3 & 70.7 & 81.3 \\
Coxsackie B3 & 83.8 & 77.8 & 75.8 & 62.5 & 67.4 & 80.0 \\
Coxsackie B4 & 80.9 & 79.6 & 74.2 & 64.2 & 72.1 & 84.9 \\
Coxsackie A9 & 83.3 & 78.3 & 74.2 & 64.6 & 71.6 & 79.9 \\
Coxsackie A16 & 81.9 & 58.8 & 63.2 & 52.1 & 64.5 & 65.7 \\
Polio 3 & 72.4 & 63.6 & 74.3 & 50.9 & 54.6 & 67.9 \\
\hline
\end{tabular}

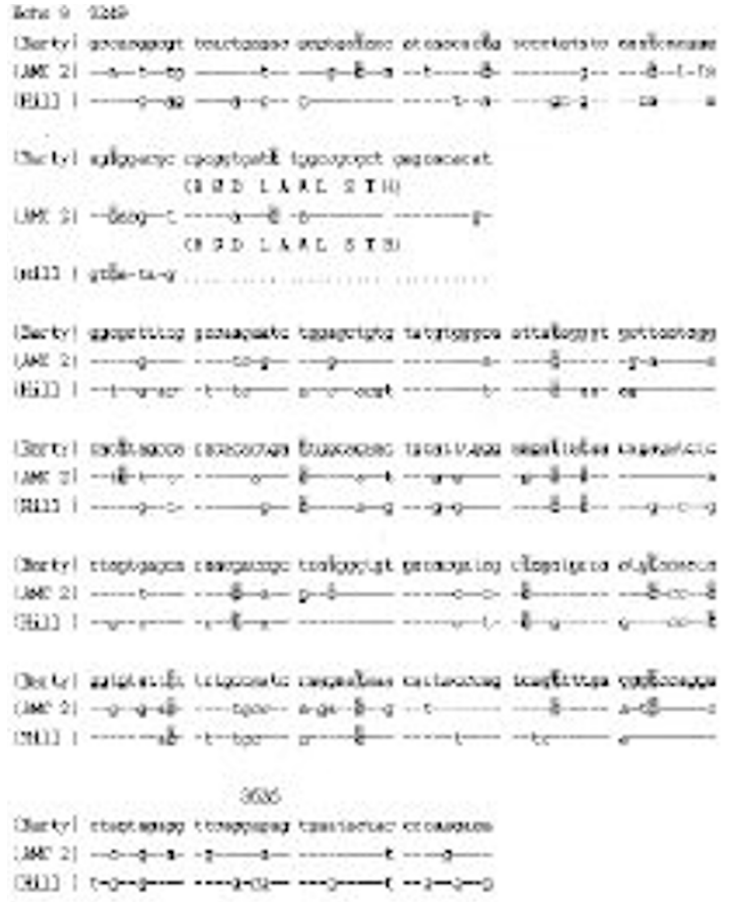

Figure 4. Nucleotide and amino acid sequence of VP1/2A region of AMC 2 isolate compared with the prototype strain Hill and Barty. Nucleotide sequences of AMC 2 isolate and echovirus 9 Hill strain are indicated by "(-)" for corresponding sequence; deletion depicted (.). The shade boxes denote for the substitutions of $U$ to $C$ or $A$ to $G$.

et al., 1998). The amplified products were sequenced and compared with the published sequence of echovirus type 9 (Figure 4, GenBank accession \#U77069). The result showed that both the extension and the RGD motif were retained in all isolates.

\section{VP1 region}

We amplified and analyzed the major recognition site for human IgG antibodies (Samuelson et al., 1995), which has been previously characterized by RT-PCR as the VP1 region of the isolates. The amino acid sequence crucial for antibody binding was completely conserved in all of the isolates (GenBank accession \#U77071), providing an explanation for the observed serological cross reactivity in the patient's sera.

\section{$2 \mathrm{C}$ region}

$2 \mathrm{C}$ region may code for a helicase involved in viral RNA strand separation during replication (Dmitrieiva et al., 1991; Teterrina et al., 1992). Thus, a 580 bp fragment of the entire $2 \mathrm{C}$ helicase coding region was amplified with primer pair $F$ (Table 1) and sequenced (GenBank accession \#U77072). The $2 \mathrm{C}$ region of the isolates shared $80 \%$ and $83 \%$ nucleotide sequence identity with Hill and Barty strains, respectively (Table 2 ). The amino acid sequences were identical in both strains.

\section{Discussion}

Echoviruses were discovered when cell culture techniques were first introduced into the virus laboratory. Although it is now widely known that echoviruses are common human pathogens, our knowledge about their molecular characteristics is relatively limited. Humans are the only known reservoir of echoviruses, and a close contact appears to be the mode of transmission via the fecaloral route. The majority of infections probably remain limited to the initially infected cells in the alimentary or respiratory tract however, the viruses occasionally disseminate beyond the primary foci to the distant organs. Enterovirus infection is diagnosed by the isolation of the virus in cell culture, followed by neutralizing typing. RT-PCR has been recently used for 
rapid and sensitive detection and identification of enteroviruses. There are numerous reports on applications of the PCR method such as multiplex PCR to distinguish between polio and nonpolio enterovirus, nested PCR for the rapid identification of human picornavirus, and the usefulness of the serotyping of PCR product by RFLP assay (Abraham et al., 1993; Egger et al., 1995; Kammerer et al., 1994; Schweiger et al., 1994).

In 1953, the prototype strain Hill of echovirus 9 isolated from rectal swab of a healthy child was found to be nonpathogenic to a newborn mice. In contrast, echovirus 9 strain Barty which was isolated during an epidemic in 1957 from the CSF of a child suffering from aseptic meningitis (Rosenwirth et al., 1986) was pathogenic. In a previous study, we showed that the isolates from CSF collected during 1993 were echovirus type 9 which exhibited pathogenicity for newborn mice. In order to identify the genetic difference of the 1993 Korea echovirus type 9 isolates comparing with Hill and Barty strain, we carried out partial sequencing of 5'-NCR, VP4-VP2, VP1 capsid protein coding region, and $2 \mathrm{C}$ helicase region. Furthermore we combined RT-PCR and RFLP assays for molecular characterization of the isolates. Based on the size and the pattern of restriction enzyme digestion of $440 \mathrm{bp}$ PCR products of the 5'-NCR region (Figures 1 and 2), we concluded that the isolates were echovirus type 9 which was consistent with our earlier identification by a neutralizing test.

However, the restriction enzyme fragment patterns were not identical to those expected of the echovirus 9 prototype strains (Figure 1B and Figure 2). To analyze the genetic variability of the isolates, we sequenced the 5 '-NCR of AMC 2 and compared the sequence with that of other enteroviruses. AMC 2 isolate share a high level $(87.6 \%)$ of nucleotide sequence identity with echovirus 9 Barty strain, suggesting that the restriction enzyme site may have been lost by mutation.

It has been demonstrated with poliovirus that 5 -terminal 90 nucleotides forms a cloverleaf-like secondary structure which is essential for replication (Skinner et al., 1989; Toyoda et al., 1993). However, such unique structure has not been observed in the isolates (data not shown). Further study is in need to clarify the significance of this variable secondary structural change. Recently, neuro-virulent echovirus serotypes are shown to possess an upstream OPT sequence of 5'-TTTCCTTTT-3' (Romero et al., 1995), and the less virulent serotype, echovirus type 2 and 12 have changes in this sequence. We found that the six isolates shared an identical nucleotide sequence with neurovirulent echovirus serotype (Figure 3 ), providing an evidence that these isolates exhibited neurovirulent phenotype.

Although we had identified the six isolates as echovirus type 9 by neutralizing test, we did not clarify exactly which strain causes aseptic meningitis. In the case of strain Barty, an additional 10 amino acid fragment including an RGD motif is inserted at the C-terminus of the capsid protein VP1 (Zimmermann et al., 1996). When we com-pared the nucleotide sequence of VP1 region of AMC 2 isolate with those of echovirus type 9 Hill and Barty strain, we found that AMC 2 isolate belonged to the Barty strain. AMC 2 isolate had a RGD motif (Figure 4), which was known to be involved in receptor interaction in a number of cellular systems, including attachment of food-and-mouth-disease virus (FMDV) to its cellular receptor. Contrary to other sequenced enteroviruses, the coxsackie virus $A 9$ sequence has an insertion in the VP1-encoding region, which encodes an apparent 17 amino acid exten-sion containing RGD sequence (Chang et al., 1992). Thus, the RGD sequence provides a possibility that coxsackie virus $A 9$ and the isolates recognize their respective receptors by the same mechanism. This is consistent with the finding that echovirus type 9 produced paralysis in a new born mice with muscle lesions similar to those which are associated with coxsackie $A$ virus.

We have observed a significant number of $U$ to $C$ and $A$ to $G$ transitions in the genomic sequence of enteroviruses (Figure 4). These transitions have been frequently observed in many RNA viruses. During the replication of antigenomes or of newly generated genomes containing $U$ to $C$ substitutions, $A$ to $G$ substitutions could be introduced in the genome template. After a round of replication, this would give rise to certain genomes having $U$ to $C$ changes and to others having both $U$ to $C$ and $A$ to $G$ changes. Biased hypermutations may be a common feature during replication of RNA viruses. The $U$ to $C$ and $A$ to $G$ transitions in echoviruses may have no significant effects on the viral RNA replication. Thus, clinical isolates with these mutations might be found frequently.

We also found that the antigenic region known to elicit cross-reactivity with enterovirus IgG antibodies in VP1 of the isolates was highly conserved as poliovirus and coxsackievirus $\mathrm{A}$ and $\mathrm{B}$. Genomic sequences in $2 \mathrm{C}$ region of the six isolates were compared with the published sequences of enteroviruses, finding the isolates being genetically closely related to echoviruses, coxsackie B virus and coxsackie virus A9. The AMC 2 isolate shared about $80 \%$ nucleotide sequence homology of the $2 \mathrm{C}$ region with Hill and Barty stains, whereas their amino acid sequences were identical. This result suggests that nonstructural proteins are not under the selection pressure caused by host antibodies.

In summary, we showed in the present study that echovirus type 9 was responsible for the outbreak of aseptic meningitis in 1993 in Korea. Based on the analysis of the VP1 region sequence, the isolates were identified as echovirus type 9 Barty strain. 


\section{Acknowledgments}

We thank Dr. Lim, W. L., QMH, Hong Kong for the serological confirmation of the isolates and Park, W.-B. for his expert technical assistance. We also thank Drs. Chin, $\mathrm{H}-\mathrm{M}$ and Kim, J-K, NINDS/NIH, for critical reading of the manusript. This study was supported by Basic Medical Research Fund from the Ministry of Education, Republic of Korea (BM96-018).

\section{References}

Abraham, R., Chonmaitree, T., Mccombs, J., Prabhakar, B., LoVerde, P. T. and Ogra, P. L. (1993) Rapid detection of poliovirus by reverse trans-cription and polymerase chain amplification: application for differentiation between poliovirus and nonpoliovirus enteroviruses. J. Clin. Microbiol. 31: 395-399

Berlin, L.E., Rorabaugh, M. L., Heldrich, F., Roberts, K.,Doran, T. and Modlin, J. F. (1993) Aseptic meningitis in infants < 2 years of age: diagnosis and etiology. 888-892. J. Infect. Dis. 168: 888-892

Chang, B. K. H., Auvinen, P., Hyypia, T. and Stanway G. (1989) The nucleotide sequence of coxsackievirus $A 9$; implications for receptor binding and enterovirus classification. J. Gen. Virol. 70: 3269-3280

Dmitrieva, T. M., Norkina, K. B. and Agol, V. I. (1991) Encephalomyocarditis virus RNA polymerase preparations, with and without RNA helicase activity. J. Virol. 65: 27142717

Egger, D., Pasamontes, L., Ostermayer, M. and Bienz, K. (1995) Reverse transcription multiplex PCR for differentiation between polio- and entero-viruse from clinical and environmental samples. J. Clin. Microbiol. 33: 1442-1447

Feigin, R. D. and Cherry, J. D. (1987) Textbook of pediatric infectious disease. 2nd Edn., pp. 478-484, WBSaunders Co, Philadelphia

Grist, N. R., Beil, E. J. and Assaad, F. (1978) Enteroviruses in human disease. Prog. Med. Virol. 24: 114-157

Hyypia, T.,Auvinen, P. andMaaronen, M. (1989) Polymerase chain reaction for human picornaviruses. J. Gen. Virol. 70: 3261-3268

Jung, Y. T. and Kim, G. R. (1995) Genomic characterization of M and S RNA segments of hantaviruses isolated from bats. Acta Virol. 39: 231-233

Jung, Y. T., Kim, G. R., Lee, S. R. and Paik, S. Y. (1998)Rapid subgrouping of nonpolio enterovirus associated with aseptic meningitis by RFLP (restriction frgment length polymolphism) assay. Mol. Cells 8 (in press)

Kammerer, U., Kunkel, B. and Korn, K. (1994) Nested PCR for specific detection and rapid identification of human picornaviruses. J. Clin. Microbiol. 32: 285-291

Kim, G. R., Lee, J. S., Jung, Y. T., Chung, Y. J. and Rhyu, M. G. (1997) Nucleotide sequencing of a part of the $5^{\prime}$-noncoding region of echovirus type 9 and rapid virus detection during the acute phase of aseptic meningitis. Arch. Virol. 142: 853-860

Kim, G. R. and McKee, K. R. Jr. (1985) Pathogenesis of Hantaan virus infection in suckling mice: clinical, virologic, and serologic observations. Am. J. Trop. Med. Hyg. 34: 388-395

Kim, M. B., Kim, K. S., Bae, Y. B., Song, C. Y., Yoon, J. D., Lee, K. H. and Shin, H. K. (1996) General primer-mediated PCR detection of enterovirus causing aseptic meningitis. J. Korean Soc. Virol. 26: 215-225

Kopecka, H., Brown, B. and Pallansch M. (1995) Genotypic variation in coxsackievirus B5 isolates from three different outbreaks in the United States. Virus Res. 38: 125-136

Lipson, S. M., Walderman, R., Costello, P. and Szabo, K. (1988) Sensitivity of rhabdomyosarcoma and guinea pig embryo cell cultures to field isolates of difficult to cultivate group A coxsackieviruses. J. Clin. Microbiol. 26: 1298-1303
Meerovitch, K., Nicholson, R. and Sonenberg, N. (1991) In vitro mutational analysis of cisacting RNA translational elements within the poliovirus type 25 untranslated region. J. Virol. 65: 5895-5901

Melnick, J. L. (1990) Enteroviruses: polioviruses, coxsackieviruses, echo-viruses and newer enteroviruses. In Virology. (Fields, B. N. and Knipe, D. M. eds.), pp. 549-605, Raven Press, New York

Nicholson, R., Pelletier, J., Le, S. Y. and Sonenberg. (1991) Structural and functional analysis of the ribosome landing pad of poliovirus type 2 : in vivo translation studies. J. Virol. 65: 5886-5894

Olive, D. M., Al-Mufti, S. and Al-Mulla, W. (1990) Detection and differen- tiation of picornaviruses in clinical samples following genomic amplification. J. Gen. Virol. 71: 21412147

Romero, J. R. and Rotbart, H. A. (1995) Sequence analysis of the down-stream 5' nontranslated region of seven echoviruses with different neuro-virulence phenotypes. J. Virol. 1370-1375

Rosenwirth, B. and Eggers H. J. (1986) Biochemistry and pathogenesity of echovirus 9: II. Mutants of echovirus 9, strain Hill, with alterd capsid surface properties. Virology 153: 248-255

Rotbart, H. A. (1991) Viralmeningitis and the aseptic meningitis syndrome. In Infections of the central nervous system. (Scheld, W. M. Whitley, R. J. and Durack, D. T. eds.), pp. 19-40, Raven Press, New York

Rotbart, H. A. (1990) Evaluation of a new bicolored latex agglutination test for immunological diagnosis of hepatic amoebiasis. J. Clin. Microbiol. 28: 1422-1424

Samuelson, A., Johansson, B. and Forsgren, M. (1995) Sequence analysis of echoviruses in a major antigenic region eliciting enteroviral cross-reactive antibodies. Arch. Virol. 140: 2085-2091

Sanger, F., Nicken, S. and Coulson, A. R. (1977) DNA sequencing with chainterminating inhibitors. Proc. Natl. Acad. Sci. U S A 74: 5463-5467

Schweiger, B., Schreier, E., Bothig, B. and Lopez-Pila, J. M. (1994) Differentiation of vaccine and wild-type polioviruses using polymerase chain reaction and restriction enzyme analysis. Arch. Virol. 134: 39-50

Skinner, M. A., Racaniello, V. R., Dunn, G., Cooper, J., Minor, P. D. and Almond, J. W. (1989) New model for the secondary structure of the $5^{\prime}$ non-coding RNA of poliovirus is supported by biochemical and genetic data that also show that RNA secondary structure is important in neurovirulence. J. Mol. Biol. 207: 379-392

Teterina, N. L., Kean, K. M., Gorbalenya, A. E., Agol, V. I. and Girard, M. (1992) Analysis of the functional significance of amino acid residues in the putative NTPbinding pattern of the poliovirus 2C protein. J. Gen. Virol. 73: 1977-1986

Toyoda, H., Kohara, M., Kataoka, Y., Suganuma, T., Omata, T., Imura, N. and Nomoto, A. (1984) Complete nucleotide sequences of all three poliovirus serotype genomes. Implication for genetic relationship, gene function and antigenic determinants. J. Mol. Biol. 174: 561-585

Xiao, S. Y., Yanagihara, R., Godec, M. S., Eldadah, Z. A., Johnson, B. K., Gajdusek, D. C. and Asher, D. M. (1991) Detection of hantavirus RNA in tissues of experimentally infected mice using reverse transcriptase-directed polymerase chain reaction. J. Med. Virol.33: 277-282

Zimmermann, H., Eggers, H.J. and Nelsen-salz B. (1996) Molecular cloning and sequence determination of the complete genome of the virulen echovirus 9 strain barty. Virus Genes. 12: 149-154

Zoll, G. J., Melchers, W. J. G., Kopecka, H., Jambroes, G., Van der Poel, H. J. A. and Galama, J. M. D. (1992) General primer-mediated polymerase chain reaction for detection of enteroviruses: application for diagnostic routine and persistent infections. J. Clin Microbiol. 30: 160-165 